Jurnal Ilmu Ilmu Agribisnis: Journal of Agribusiness Science, 9(2), Mei 2021

\title{
ANALISIS EFISIENSI DISTRIBUSI DAN TINGKAT KETEPATAN PENDISTRIBUSIAN PROGRAM RASTRA DAN BPNT PADA RUMAH TANGGA PENERIMA MANFAAT DI KELURAHAN YUKUM JAYA, KABUPATEN LAMPUNG TENGAH
}

\author{
(Analysis of distribution efficiency and distribution accuracy level of RASTRA and BPNT assistance at \\ beneficiary households in Yukum Jaya Village, Central Lampung Regency)
}

Annisa Nevy Prihartini, Raden Hanung Ismono, dan Zainal Abidin

\begin{abstract}
Jurusan Agribisnis, Fakultas Pertanian, Universitas Lampung, Jl. Prof. Dr. Soemantri Brojonegoro No. 1 Bandar Lampung 35145, e-mail: hanung.ismono@fp.unila.ac.id
\end{abstract}

\begin{abstract}
This study aims to determine the distribution system, efficiency, and accuracy of the distribution of Beras Sejahtera (RASTRA) and Bantuan Pangan Non-Tunai (BPNT) programs in Yukum Jaya Village, Terbanggi Besar Sub-district, Central Lampung Regency. The attributes used in this study are right on target, right on amount, right on time, right on price, right on administration, right on quality consisting of color, aroma, rice cleanliness, and condition of eggs. The study uses a survey method involving 33 recipients of Rastra program and 31 recipients of BPNT program. The first and second objectives are analyzed using qualitative and quantitative descriptive analysis. The third objective is analyzed using Customer Satisfaction Index (CSI) and Importance Performance Analysis (IPA). The study shows that the distribution system of Rastra and BPNT are included in the semi-direct distribution category. The distribution efficiency of the Rastra program is $0 . .06$ and the BPNT program is 0.04 which means that the distribution of rice in the two programs are efficient. The CSI of Rastra score is $54.36 \%$ or in quite proper category and BPNT is $68.94 \%$ or proper category. IPA analysis shows that the most suitable attribute of Rastra is the right on price attribute and for BPNT is the right on amount atrribute.
\end{abstract}

Key words: accurate, BPNT, CSI, efficiency, Rastra

\section{PENDAHULUAN}

Kemiskinan merupakan suatu keadaan dimana penduduknya serba kekurangan yang dilihat dari rendahnya pendapatan (Nugroho dan Dahuri, 2004). Rendahnya pendapatan penduduk miskin mengakibatkan terjadinya penurunan produktivitas dan meningkatkan beban ketergantungan bagi masyarakat. Penyebab terjadinya kemiskinan dibagi menjadi dua faktor, yaitu faktor internal dan faktor eksternal. Faktor internal adalah penyebab kemiskinan yang potensinya berasal dari diri seseorang atau keluarga serta lingkungan sekitarnya, sedangkan faktor eksternal adalah faktor yang berkaitan dengan kebijakan pemerintah yang mengakibatkan seseorang jatuh miskin karena kurangnya bahan baku atau bencana alam.

Pada tahun 2017 jumlah penduduk Provinsi Lampung menempati posisi nomor ketujuh dengan jumlah penduduk miskin terbesar di Indonesia dengan jumlah penduduk miskin sebesar 1.083,74 ribu. Kabupaten Lampung Tengah menempati posisi kedua dengan jumlah penduduk miskin tertinggi di Provinsi Lampung yaitu sebesar 162,38 ribu jiwa. Kabupaten Lampung Tengah masih terdapat banyak penduduk yang masuk ke dalam kategori miskin, oleh karena itu perlu adanya upaya pemerintah untuk meningkatkan kesejahteraan penduduk di Kabupaten Lampung Tengah.

Pemerintah mengadakan berbagai program kebijakan yang dapat meningkatkan akses bagi masyarakat terhadap pangan sebagai upaya dalam mengurangi kemiskinan. Salah satu program pemerintah untuk membantu penduduk kategori miskin adalah Program Beras Sejahtera (Rastra) pada tahun 2017, namun pada akhir tahun 2018 program penyaluran bantuan pemerintah untuk menanggulangi kemiskinan diganti nama dengan Bantuan Pangan Non-Tunai (BPNT) yang dilaksanakan dengan mekanisme nontunai menggunakan teknologi e-voucher yang berguna agar penyaluran dapat mudah terjangkau.

Berdasarkan pemantauan lapangan di Kelurahan Yukum Jaya, Kecamatan Terbanggi Besar, Kabupaten Lampung Tengah terdapat beberapa masalah yang terjadi mengenai salah sasaran yang disebabkan kesalahan data jumlah keluarga miskin, jumlah beras yang dibagikan tidak sesuai dan beras 
yang dibagikan masih kurang bersih karena terdapat campuran batuan kecil di dalam beras. Hal ini yang mengindikasi adanya masalah terhadap tingkat kepuasan pada rumah tangga penerima manfaat, sehingga perlu diteliti tentang sistem distribusi, tingkat efisiensi dan tingkat ketepatan berdasarkan kepuasan pada program bantuan Rastra dan BPNT pada rumah tangga penerima manfaat di Kelurahan Yukum Jaya, Kecamatan Terbanggi Besar, Kabupaten Lampung Tengah.

\section{METODE PENELITIAN}

Metode penelitian yang digunakan adalah survei dengan lokasi penelitian di Kelurahan Yukum Jaya Kecamatan Terbanggi Besar Kabupaten Lampung Tengah. Penentuan lokasi dilakukan secara sengaja (purposive) dengan pertimbangan bahwa , lokasi ini dipilih karena jumlah penerima manfaat bantuan di Kelurahan Yukum Jaya yang cukup tinggi pada Kabupaten Lampung Tengah. Waktu pengumpulan data dan pelaksanaan penelitian dilakukan pada bulan Juli 2019-Agustus 2019.

Responden penelitian dipilih menggunakan teknik acak sederhana (Simple Random Sampling), yaitu rumah tangga penerima manfaat bantuan program Rastra dan BPNT yang sudah terdaftar di Kelurahan Yukum Jaya. Responden penelitian ini adalah keluarga penerima manfaat di Kelurahan Yukum Jaya Kecamatan Terbanggi Besar Kabupaten Lampung Tengah, sebanyak 33 penerima Rastra dan 31 penerima BPNT. Uji validitas dan reliabilitas digunakan untuk mengetahui setiap butir pertanyaan yang akan diajukan kepada seseorang sudah valid atau belum. Pada uji validitas nilai yang dapat dikatakan baik apabila nilai corrected item dari total correlation bernilai di atas 0,20.

Tabel 1. Hasil uji validitas dan reliabilitas atribut tingkat kepentingan program Rastra dan BPNT

\begin{tabular}{clcc}
\hline \multirow{2}{*}{ No } & Atribut produk & 0,255 & 0,581 \\
\cline { 3 - 4 } & & \multicolumn{2}{c}{$\begin{array}{c}\text { Corrected Item- } \\
\text { Total Correlation }\end{array}$} \\
\hline 1 & Sasaran Penerima & 0,273 & 0,370 \\
2 & Sesuai Jumlah & 0,243 & 0,674 \\
3 & Memenuhi Kebutuhan & 0,272 & 0,248 \\
4 & Waktu Pendistribusian & 0,347 & 0,596 \\
5 & Warna Beras & 0,591 & 0,599 \\
6 & Aroma Beras & 0,377 & 0,305 \\
7 & Kebersihan Beras & - & 0,624 \\
8 & Kondisi Telur & 0,384 & 0,343 \\
9 & Sesuai Harga & 0,316 & 0,555 \\
10 & Adanya Pendataan & 0,660 & 0,810 \\
\hline \multicolumn{2}{c}{ Cronbach's Alpha }
\end{tabular}

Tabel 2. Hasil uji validitas dan reliabilitas atribut tingkat kinerja program Rastra dan BPNT

\begin{tabular}{|c|c|c|c|}
\hline \multirow[t]{2}{*}{ No } & \multirow[t]{2}{*}{ Atribut produk } & \multicolumn{2}{|c|}{$\begin{array}{l}\text { Corrected Item- } \\
\text { Total Correlation }\end{array}$} \\
\hline & & Rastra & BPNT \\
\hline 1 & Sasaran Penerima & 0,235 & 0,202 \\
\hline 2 & Sesuai Jumlah & 0,333 & 0,289 \\
\hline 3 & Memenuhi Kebutuhan & 0,416 & 0,591 \\
\hline 4 & Waktu Pendistribusian & 0,342 & 0,313 \\
\hline 5 & Warna Beras & 0,430 & 0,362 \\
\hline 6 & Aroma Beras & 0,617 & 0,668 \\
\hline 7 & Kebersihan Beras & 0,579 & 0,240 \\
\hline 8 & Kondisi Telur & - & 0,288 \\
\hline 9 & Sesuai Harga & 0,364 & 0,268 \\
\hline \multirow[t]{2}{*}{10} & Adanya Pendataan & 0,317 & 0,256 \\
\hline & Cronbach's Alpha & 0,727 & 0,684 \\
\hline
\end{tabular}

Apabila nilai korelasi butir corrected item dari butir otal correlation sudah di atas 0,20 maka nilai butir-butir tersebut dikatakan valid (Sufren dan Natanael, 2013). Suatu kuesioner juga dikatakan reliabel jika jawaban seseorang terhadap pertanyaan yang diberikan tersebut konsisten dari waktu ke waktu, setiap pertanyaan dikatakan reliabel jika nilai nilai cronbach alpha $>\mathrm{r}$ tabel. Nilai $r$ tabel yang digunakan adalah 0,60 (Ghozali, 2002). Untuk mengetahui valid dan reliabel suatu kuisioner dapat digunakan rumus berikut:

$\mathrm{r}=\left[\frac{\mathrm{k}}{(\mathrm{k}-1)}\right]\left[1-\frac{\sum \sigma \mathrm{b}^{2}}{\sigma \mathrm{t}^{2}}\right]$

Keterangan:

$\mathrm{r} \quad=$ koefisien reliability instrument

$\mathrm{k} \quad=$ banyaknya butir pertanyaan

$\sum \sigma b^{2}=$ total varians butir

$\Sigma \mathrm{t}^{2} \quad=$ total varians

Terdapat 9 atribut penelitian yang akan digunakan untuk program Beras Rastra dan 10 atribut untuk program BPNT di Kelurahan Yukum Jaya.. Berdasarkan hasil uji validitas dan uji reliabilitas tingkat kepentingan dan kinerja, atribut-atribut pada program bantuan Rastra dan BPNT dapat dikatakan valid dan reliabel karena, nilai corrected item dari total correlation diatas 0,20 dan nilai cronbach alpha diatas 0,60. Hasil uji validitas dan reliabilitas tingkat kepentingan dan kinerja terhadap program Rastra dan BPNT disajikan pada Tabel 1 dan 2

Metode analisis data yang digunakan dalam penelitian ini adalah menggunakan analisis deskriptif kualitatif dan deskriptif kuantitatif. Dibawah ini merupakan metode analisis data yang digunakan dalam penelitian, yaitu: 
Analisis untuk mengetahui sistem distribusi program Rastra dan BPNT dengan menggunakan analisis deskriptif kualitatif. Menurut Sugiyono (2005) metode deskriptif adalah suatu metode yang digunakan untuk menganalisis suatu hasil penelitian namun tidak digunakan untuk membuat kesimpulan yang lebih luas. Penelitian kualitatif merupakan sebuah penelitian yang bertujuan untuk memperoleh wawasan tentang suatu topik tertentu. Teknik metode wawancara dan observasi yang digunakan dalam penelitian kualitatif pada umumnya.

Analisis untuk mengetahui tingkat efisiensi penyaluran Rastra dan BPNT menggunakan analisis deskriptif kuantitatif dengan menghitung biaya distribusi di tingkat lembaga distribusi dan nilai jual beras yang dipasarkan. Efisiensi distribusi merupakan salah satu ukuran baik atau tidaknya suatu distribusi. Kegiatan ekonomi produktif selalu berkaitan dengan efisiensi ekonomi. Tujuan distribusi yang ingin dicapai adalah biaya distribusi yang mencukupi selama proses pendistribusian dan pembagian Rastra dan BPNT. Analisis tingkat efisiensi distribusi beras miskin dihitung dengan menggunakan rumus efisiensi distribusi (Ed) sebagai berikut :

$$
\mathrm{Ed}=\frac{\text { Biaya distribusi }}{\text { Nilai produk }} \times 100 \% \text {. }
$$

\section{Kriteria:}

a. Ep $\geq 1$ berarti pendistribusian tidak efisien

b. Ep $<1$ berarti pendistribusian efisien (Downey dan Erickson, 1992)

Biaya distribusi dari program Rastra dan BPNT yaitu meliputi biaya tenaga kerja dalam menyalurkan, biaya transportasi untuk menyalurkan, biaya upah buruh bongkar di lokasi titik distribusi, biaya susut dan biaya upah menimbang.

Costumer Satisfaction Index (CSI) merupakan metode analisis yang digunakan untuk mengetahui tingkat ketepatan program berdasarkan kepuasan penerima manfaat terhadap suatu produk tertentu disuatu tempat. Menurut Supranto (2006) metode CSI digunakan sebagai alat untuk menentukan tingkat ketepatan pendistribusian berdasarkan kepuasan penerima manfaat secara menyeluruh dengan mempertimbangkan tingkat kepentingan dari atribut-atribut yang diukur. Beberapa tahap dalam menghitung CSI sebagai berikut:
Mean importance score (MIS)

$\mathrm{MIS}=\frac{\sum_{\mathrm{i}=1}^{\mathrm{n}} \mathrm{Yi}}{\mathrm{N}}$

Weighting factor (WF)

$\mathrm{WF}=\frac{\mathrm{MISi}}{\sum_{\mathrm{i}=1}^{\mathrm{p}} \mathrm{MISi}}$

Weighting score (WS)

$\mathrm{WS}_{\mathrm{i}}=\mathrm{WF}_{\mathrm{i}} \times \mathrm{MSS}$.

Weighted total (WAT)

$\mathrm{WAT}=\sum \mathrm{WS}$.

Customer satisfaction index (CSI

$\mathrm{CSI}=\frac{\sum_{\mathrm{i}=1}^{\mathrm{p}} \mathrm{MISi}}{\mathrm{HS}} \mathrm{x} 100 \%$

Menurut Supranto (2006) terdapat beberapa rentang skala dan interpretasi pada analisis CSI secara Keseluruhan, untuk rentang skala 0,00-0,21 (sangat tidak tepat), 0,21-0,040 (tidak tepat), 0,410,60 (cukup tepat), 0,61-0,80 (tepat), dan 0,81-1,00 (sangat tepat).

Analisis metode Importance Performance Analysis (IPA) digunakan untuk menentukan tingkat ketepatan berdasarakan atribut-atribut pada program Rastra dan BPNT. Metode IPA merupakan suatu teknik yang digunakan untuk mengukur atribut suatu produk berdasarkan tingkat kepentingan dengan tingkat kinerja. Metode IPA juga dapat menggambarkan posisi atribut-atribut suatu produk dalam diagram yang disebut diagram kartesius yang terdiri dari empat bagian.

\section{HASIL DAN PEMBAHASAN}

\section{Sistem Distribusi Program Rastra dan BPNT}

Pada awalnya program bantuan dari pemerintah disebut dengan program Operasi Pasar Khusus (OPK), kemudian diubah menjadi Beras Sejahtera (Rastra) pada tahun 2002, Rastra diperluas fungsinya tidak lagi menjadi program darurat (social safety net) melainkan sebagai bagian dari program bantuan perlindungan sosial masyarakat (Bulog, 2018).

Perum Bulog bersama Tim Koordinasi Rastra menyusun rencana penyaluran bulanan yang dituliskan dalam Surat Permintaan Alokasi (SPA). Bantuan Rastra disalurkan oleh Perum BULOG ke titik distribusi yaitu lokasi titik distribusi bantuan yang telah disepakati oleh Perum BULOG dan Pemerintah kabupaten Lampung Tengah. 
Selanjutnya, Pelaksanaan penyaluran bantuan Rastra di Kelurahan Yukum Jaya berdasarkan surat Sekda Kota Bandar Jaya perihal penyaluran rastra yang dilaksanakan pada akhir bulan biasanya dibagikan kepada KPM pada tangal 24 - 30 setiap bulannya. Penerima manfaat dipilih berdasarkan kriteria bahwa masyarakat yang bersangkutan berpendapatan rendah didaerah tempat tinggalnya.

Titik-titik penyaluran dilakukan oleh Pihak Kecamatan dan Kelurahan Yukum Jaya. Berdasarkan data yang diperoleh peneliti terdapat sebanyak 932 kepala keluarga yang ada di 25 Lingkungan Kelurahan Yukum Jaya dan jumlah beras yang diterima sebanayak $5 \mathrm{~kg}$ dengan harga jual Rp 1.600/kg. Apabila bantuan Rastra dan uang pembayaran sudah sampai di kelurahan selanjutnya, pihak kelurahan membuat surat kepada para ketua RW untuk mengambil Rastra dan uang yang telah terkumpul di kelurahan, kemudian RW menyerahkan kepada ketua RT masing-masing untuk dibagikan kepada penerima manfaat.

Program BPNT di Kelurahan Yukum Jaya telah berlangsung sejak awal tahun 2018, dimana program BPNT merupakan salah satu bentuk bantuan penanggulangan masyarakat miskin yang diberikan oleh pemerintah dengan jumlah $\mathrm{Rp}$ 110.000/bulan yang dapat dicairkan menjadi bahan pokok seperti beras dan telur. Penerima manfaat ditentukan oleh pemerintah setempat dengan kriteria keluarga yang memiliki penghasilan rendah. Selanjutnya, penerima manfaat akan mendapatkan surat pemberitahuan berisi teknis pendaftaran di tempat yang telah ditentukan. Data yang telah diisi oleh calon penerima program ini lalu diproses secara paralel dan sinergis oleh bank yang tergabung dalam Himpunan Bank Milik Negara (Himbara), kantor kelurahan dan kantor walikota/ kabupaten.

Setelah verifikasi data selesai, penerima bantuan sosial akan dibukakan rekening di bank dan mendapatkan Kartu Keluarga Sejahtera (KKS) yang berfungsi sebagai kartu non tunai untuk pengambilan bantuan pangan. Penerima bantuan sosial yang telah memiliki KKS dapat langsung datang ke e-warong (Elektronik Warung Gotong Royong) terdekat untuk melakukan transaksi pembelian bahan pangan menggunakan KKS.

Penerima manfaat dapat membeli bahan pangan sesuai kebutuhan pada e-warong yang memiliki tanda lokasi penyaluran bantuan sosial non tunai. Transaksi dilakukan secara non tunai mengacu pada jumlah saldo yang tersimpan pada chip KKS.
Sistem distribusi dari program Rastra dan BPNT berada dalam kategori distribusi semi langsung karena dilaksanakan melalui saluran yang dimiliki oleh penyalur, pihak penyalur memiliki produsen/ perusahaan sebagai perantara untuk mengantarkan bantuannya kepada penerima manfaat. Perantara nya melalui beberapa pelaku yang terkait.

Proses penyaluran bantuan Rastra menurut anjuran pemerintah dari segi jumlah, sebaiknya bantuan yang dibagikan harus sesuai dengan jumlah yang telah ditetapkan oleh pemerintah sebesar $15 \mathrm{~kg} /$ bulan, namun pada kenyataannya proses penyaluran bantuan Rastra di Kelurahan Yukum Jaya, Kecamatan Terbanggi Besar, Kabupaten Lampung Tengah belum berjalan dengan baik hal ini dikarenakan, jumlah yang dibagikan tidak sesuai dengan ketetapan dari pemerintah yaitu hanya sebesar $5 \mathrm{~kg} /$ bulan. Hal ini disebabkan karena pembagian bantuan dibagikan keseluruh masyarakat secara merata dan menyebabkan masih ada kesalahan pada saat pendataan, akibatnya orang yang mampu pun mendapatkan bantuan beras tersebut.

Proses penyaluran BPNT di Kelurahan Yukum Jaya, Kecamatan Terbanggi Besar, Kabupaten Lampung Tengah sudah berjalan cukup baik, karena dengan adanya pendataan yang baik maka pembagian bantuan sudah sesuai dengan kebutuhan penerima manfaat, hanya saja terdapat ketidaksesuaian produk BPNT yang dapat dilihat dari kualitas beras itu sendiri karena masih belum layak untuk dikonsumsi bukan berarti tidak dapat dikonsumsi. Hal tersebut tidak sesuai dengan salah satu tujuan diadakannya program BPNT yaitu untuk mengurangi beban pengeluaran Keluarga Penerima Manfaat (KPM) melalui pemenuhan sebagian kebutuhan pangan.

\section{Efisiensi Distribusi Program Rastra dan BPNT}

Kelurahan Yukum Jaya memiliki RTS-PM pada program Rastra sebanyak 932 penerima. Dengan total pagu Rastra sebesar $4.660 \mathrm{~kg}$. Biaya-biaya distribusi yang diperlukan dalam kedua pendistribusian program bantuan, seperti biaya angkutan atau transportasi, biaya tenaga kerja dan biaya upah buruh bongkar di lokasi titik distribusi. Total penjualan pada program Rastra sebesar Rp7.456.000. Pada proses pendistribusian program Rastra di Kelurahan Yukum Jaya, terdapat biaya distribusi yang meliputi biaya transportasi, dan biaya upah buruh bongkar di lokasi titik distribusi. Adapun total biaya distribusi program Rastra adalah sebesar Rp451.000. Kelurahan 
Yukum Jaya memiliki RTS-PM pada program BPNT sebanyak 225 penerima. Dengan dan total pagu BPNT sebesar $2.362,50 \mathrm{~kg}$. Total penjualan pada program BPNT sebesar Rp24.750.000. Pada proses pendistribusian program BPNT di Kelurahan Yukum Jaya, terdapat biaya distribusi yang meliputi biaya transportasi, biaya tenaga kerja dan biaya upah buruh bongkar di lokasi titik distribusi.

Adapun total biaya distribusi pada program BPNT adalah sebesar Rp1.120.000. Di bawah ini adalah hasil dari perhitungan efisiensi distribusi (Ed) dari program bantuan pemerintah Rastra dan BPNT di Kelurahan Yukum Jaya, Kecamatan Terbanggi Besar, Kabupaten Lampung Tengah:

$$
\begin{aligned}
& \text { Ed }=\frac{451.000}{7.456 .000} \times 100 \%=0,06 \\
& E d=\frac{1.120 .000}{24.750 .000} \times 100 \%=0,04
\end{aligned}
$$

Nilai efisiensi distribusi program Rastra di Kelurahan Yukum Jaya adalah sebesar 0,06. Hasil penelitian ini sejalan dengan penelitian yang dilakukan Silalahi, Salmiah dan Roem (2014) menunjukkan bahwa efisiensi Raskin di Desa Hamparan Perak sudah efisien dengan efisiensi distribusi sebesar 0,08. Nilai efisiensi distribusi BPNT di Kelurahan Yukum Jaya adalah sebesar 0,04 .

Hasil penelitian ini sejalan dengan penelitian yang dilakukan Ekafitri, Hasyim dan Soelaiman (2014) menunjukkan bahwa efisiensi raskin di Kelurahan Kangkung adalah sebesar 0,04. Hal ini menunjukkan pendistribusian program Rastra dan BPNT pada Kelurahan Yukum Jaya termasuk efisien, dikarenakan hasil perhitungan efisiensi distribusi kedua program tersebut di bawah satu. Efisiensi pendistribusian Rastra dan BPNT di Kelurahan Yukum Jaya, Kecamatan Terbanggi Besar, Kabupaten Lampung Tengah dapat dilihat pada Tabel 3.

Tabel 3. Efisiensi distribusi program Rastra dan BPNT di Kelurahan Yukum Jaya

\begin{tabular}{lrr}
\hline \multicolumn{1}{c}{ Uraian } & \multicolumn{1}{c}{ Ratsra } & \multicolumn{1}{c}{ BPNT } \\
\hline Jumlah RTS-PM & 932 & 225 \\
Total Pagu (Kg) & 4660 & 2362,5 \\
Harga jual/kg (Rp) & $1.600,00$ & $110.000,00$ \\
Total penjualan (Rp) & $7.456 .000,00$ & $24.750 .000,00$ \\
Total Biaya Distribusi (Rp) & $451.000,00$ & $1.120 .000,00$ \\
Efisiensi Distribusi & 0,06 & 0,04 \\
\hline
\end{tabular}

\section{Customer Satisfaction Index (CSI)}

CSI merupakan indikator untuk mengukur tingkat ketepatan program berdasarkan kepuasan penerima manfaat dapat dinilai berdasarkan penilaian terhadap tingkat kepentingan dengan tingkat kepercayaan atribut. Perhitungan berdasarkan CSI dapat dilihat pada Tabel 4 dan Tabel 5.

Dapat dilihat pada Tabel 4 bahwa nilai CSI pada program Rastra sebesar 54,36 persen. Nilai CSI berada pada rentang skala 41-60 persen dan menunjukkan bahwa indeks kepuasan penerima manfaat pada program Rastra berada pada kriteria cukup tepat. Hasil penelitian ini sejalan dengan penelitian yang dilakukan Thamrin, Novita dan Tanjung (2017) menunjukkan bahwa nilai CSI pada program bantuan Raskin merasa cukup tepat dengan persentase sebesar 55 persen. Berdasarkan Tabel 5 dapat dilihat bahwa nilai CSI pada program BPNT sebesar 68,94 persen. Nilai CSI berada pada rentang skala $60-80$ persen dan menunjukkan bahwa indeks kepuasan penerima manfaat pada program BPNT berada pada kriteria tepat. Hasil penelitian ini sejalan dengan penelitian yang dilakukan Junaidi, Setiawan dan Prastiwi (2017) menujukkan bahwa nilai CSI pada program BPNT berada pada kriteria tepat dengan persentase sebesar 74,3 persen.

\section{Importance Performance Analysis (IPA)}

Metode Importance Performance Analysis (IPA) merupakan suatu metode yang dapat digunakan sebagai alat bantu dalam menentukan tingkat ketepatan pendistribusian program berdasarkan kepuasan penerima manfaat dengan melihat atribut-atribut yang dianggap penting dan sesuai dengan harapan penerima manfaat di dalam diagram kartesius.

\begin{tabular}{|c|c|c|c|c|}
\hline \multirow{2}{*}{ Atribut } & RSP & WF & RSK & \multirow{2}{*}{$\begin{array}{c}\text { WS } \\
\begin{array}{c}\text { weighted } \\
\text { score }\end{array}\end{array}$} \\
\hline & \multicolumn{2}{|l|}{ ei } & $\mathrm{Bi}$ & \\
\hline Sasaran Penerima & 4,03 & 0,11 & 1,61 & 0,17 \\
\hline Sesuai Jumlah & 4,48 & 0,12 & 1,70 & 0,20 \\
\hline Memenuhi & & & & \\
\hline Kebutuhan & 4,58 & 0,12 & 2,58 & 0,31 \\
\hline Waktu & & & & \\
\hline Pendistribusian & 4,12 & 0,11 & 2,97 & 0,33 \\
\hline Warna Beras & 3,76 & 0,10 & 2,91 & 0,29 \\
\hline Aroma Beras & 4,06 & 0,11 & 3,06 & 0,33 \\
\hline Kebersihan Beras & 4,33 & 0,12 & 3,09 & 0,36 \\
\hline Sesuai Harga & 4,30 & 0,11 & 3,61 & 0,41 \\
\hline Adanya Pendataan & 3,97 & 0,11 & 3,00 & 0,32 \\
\hline Weighted Total & 37,64 & & & 2,72 \\
\hline CSI & & & & 54,36 \\
\hline
\end{tabular}

Tabel 4. Perhitungan CSI program Rastra 
Tabel 5. Perhitungan CSI program BPNT

\begin{tabular}{lcccr}
\hline \multirow{1}{*}{ Atribut } & RSP & WF & RSK & \multicolumn{2}{c}{ WS } \\
\cline { 2 - 5 } & ei & & bi & weighted score \\
\hline $\begin{array}{l}\text { Sasaran Penerima } \\
\text { Sesuai Jumlah }\end{array}$ & 4,45 & 0,10 & 3,74 & 0,38 \\
$\begin{array}{l}\text { Memenuhi } \\
\text { Kebutuhan }\end{array}$ & 4,23 & 0,10 & 4,13 & 0,40 \\
Waktu & 4,42 & 0,10 & 3,42 & 0,35 \\
Pendistribusian & 4,39 & 0,10 & 4,16 & 0,42 \\
Warna Beras & 4,45 & 0,10 & 3,06 & 0,31 \\
Aroma Beras & 4,29 & 0,10 & 3,16 & 0,31 \\
Kebersihan Beras & 4,52 & 0,10 & 1,81 & 0,19 \\
Kondisi Telur & 4,06 & 0,09 & 3,48 & 0,33 \\
Sesuai Harga & 4,35 & 0,10 & 3,84 & 0,38 \\
Adanya Pendataan & 4,29 & 0,10 & 3,74 & 0,37 \\
\hline \multicolumn{1}{c}{ Weighted Total } & 43,45 & & & 3,45 \\
\hline \multicolumn{1}{c}{ CSI } & & & & 68,94 \\
\hline
\end{tabular}

Berdasarkan hasil perhitungan menggunakan metode CSI, tingkat ketepatan pendistribusian berdasarkan kepuasan penerima manfaat program Rastra dan BPNT masih berada dalam kategori cukup tepat dan tepat, oleh karena itu pemerintah masih harus meningkatkan kinerja usahanya agar dapat memperoleh hasil yang maksimal untuk bantuan-bantuan pemerintah di program selanjutnya agar lebih baik lagi dengan cara meningkatkan kinerja pada masing-masing atribut yang ada pada program Rastra dan BPNT. Berdasarkan hasil analisis pada Tabel 6 dapat diketahui bahwa atribut program Rastra, atribut yang masuk dalam kategori sangat sesuai antara tingkat kepentingan dengan tingkat kinerja (84\%) adalah atribut sesuai harga. Hasil penelitian ini sejalan dengan penelitian yang dilakukan Thamrin, Novita dan Tanjung (2017) menunjukkan bahwa atribut program yang paling sesuai antara tingkat kepentingan dengan tingkat kinerja (94\%) adalah tepat harga. Atribut yang masuk dalam kategori kurang sesuai antara tingkat kepentingan dengan tingkat kinerja (38\%) dan (40\%) adalah atribut sesuai jumlah dan atribut sasaran penerima. Nilai $\mathrm{X}$ (performance) dan Y (importance) dari atributatribut yang ada pada Tabel 6 kemudian dimasukkan kedalam diagram matriks IPA.

Adapun hasil dari diagram matriks dari program bantuan pemerintah Rastra di Kelurahan Yukum Jaya Kecamatan Terbanggi Besar Kabupaten Lampung Tengah sebagai berikut:

\section{Kuadran I ( Prioritas Utama )}

Atribut-tribut yang masuk dalam kuadran I adalah sesuai jumlah dan memenuhi kebutuhan. Pada pelaksanaannya, dua atribut tersebut masih jauh dari harapan penerima manfaat sehingga masih perlu ditingkatkan agar mencapai kepuasan maksimal.
Tabel 6. Hasil bobot dan rata-rata dari penilaian kinerja dan kepentingan terhadap atribut program Rastra

\begin{tabular}{|c|c|c|c|c|c|c|}
\hline Atribut & $\mathrm{BKi}$ & $\mathrm{X}$ & BK & $\mathrm{Y}$ & $\mathrm{TKi}$ & Ket \\
\hline $\begin{array}{l}\text { Sasaran } \\
\text { Penerima }\end{array}$ & 53 & 1,61 & 133 & 4,03 & 40 & $\begin{array}{r}\text { kurang } \\
\text { sesuai }\end{array}$ \\
\hline $\begin{array}{l}\text { Sesuai } \\
\text { Jumlah }\end{array}$ & 56 & 1,7 & 148 & 4,48 & 38 & $\begin{array}{r}\text { kurang } \\
\text { sesuai }\end{array}$ \\
\hline $\begin{array}{l}\text { Memenuhi } \\
\text { Kebutuhan }\end{array}$ & 85 & 2,58 & 156 & 4,73 & 54 & $\begin{array}{l}\text { cukup } \\
\text { sesuai }\end{array}$ \\
\hline $\begin{array}{l}\text { Waktu } \\
\text { Distribusi }\end{array}$ & 98 & 2,97 & 141 & 4,27 & 70 & sesuai \\
\hline $\begin{array}{l}\text { Warna } \\
\text { Beras }\end{array}$ & 96 & 2,91 & 124 & 3,76 & 77 & sesuai \\
\hline $\begin{array}{l}\text { Aroma } \\
\text { Beras }\end{array}$ & 101 & 3,06 & 134 & 4,06 & 75 & sesuai \\
\hline $\begin{array}{l}\text { Kebersihan } \\
\text { Beras }\end{array}$ & 102 & 3,09 & 143 & 4,33 & 71 & sesuai \\
\hline $\begin{array}{l}\text { Sesuai } \\
\text { Harga }\end{array}$ & 119 & 3,61 & 142 & 4,3 & 84 & $\begin{array}{l}\text { sangat } \\
\text { sesuai }\end{array}$ \\
\hline $\begin{array}{l}\text { Adanya } \\
\text { Pendataan }\end{array}$ & 99 & 3,00 & 131 & 3,97 & 76 & sesuai \\
\hline Jumla & & 24,53 & & 37,63 & & \\
\hline Rata-rata & & 2,72 & & 4,18 & & \\
\hline
\end{tabular}

Keterangan:

$\mathrm{BKi}=$ Bobot kinerja

$\mathrm{BK}=$ Bobot kepentingan

Tki $=$ Tingkat kesesuaian

\section{Kuadran II (Pertahankan Prestasi)}

Kuadran II menunjukkan atribut-atribut yang dianggap penting oleh penerima manfaat dan telah berhasil melaksanakan kinerjanya. Atribut yang masuk dalam kuadran ini adalah kebersihan beras dan sesuai harga.

\section{Kuadran III (Prioritas Rendah)}

Kuadran III menunjukkan bahwa pelaksanaanya biasa saja dan atribut-atribut yang dianggap kurang penting. Atribut yang berada pada kuadran III adalah atribut sasaran penerima.

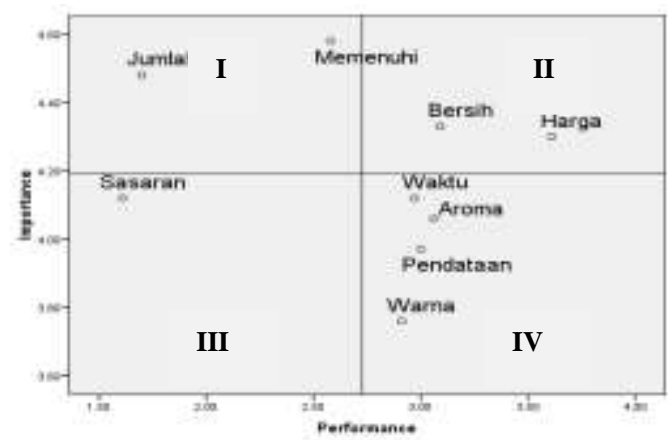

Gambar 1. Diagram kartesius IPA program Rastra Kuadran II (Pertahankan Prestasi) 


\section{Kuadran IV (Berlebihan)}

Kuadran IV menunjukkan bahwa atribut yang dinilai kurang penting, akan tetapi pelaksanaanya berlebihan. Atribut-atribut yang masuk dalam kuadaran ini adalah waktu pendistribusian. Berdasarkan hasil analisis pada Tabel 7 dapat diketahui bahwa atribut program BPNT di Kelurahan Yukum Jaya. Atribut yang masuk dalam kategori sangat sesuai $(98 \%)$ antara kinerja dan harapannya adalah atribut sesuai jumlah sedangkan atribut yang masuk dalam kategori kurang sesuai $(40 \%)$ antara kinerja dan harapannya adalah atribut kebersihan beras. Nilai $\mathrm{X}$ dan $\mathrm{Y}$ yang ada pada Tabel 7 kemudian dimasukkan kedalam diagram matriks.

\section{Kuadran I ( Prioritas Utama )}

Atribut-atribut yang masuk dalam kuadran I adalah atribut kebersihan beras, warna beras dan memenuhi kebutuhan. Atribut-atribut tersebut masih jauh dari harapan penerima manfaat sehingga perlu ditingkatkan agar penerima menjadi puas.

Tabel 7. Hasil bobot dan rata-rata dari penilaian kinerja dan kepentingan terhadap atribut program BPNT

\begin{tabular}{|c|c|c|c|c|c|c|}
\hline Atribut & $\mathrm{BKi}$ & $\mathrm{X}$ & $\mathrm{BK}$ & $\mathrm{Y}$ & $\mathrm{TKi}$ & Ket \\
\hline $\begin{array}{l}\text { Sasaran } \\
\text { Penerima }\end{array}$ & 116 & 3,74 & 138 & 4,45 & 84 & $\begin{array}{l}\text { sangat } \\
\text { sesuai }\end{array}$ \\
\hline $\begin{array}{l}\text { Sesuai } \\
\text { Jumlah }\end{array}$ & 128 & 4,13 & 131 & 4,23 & 98 & $\begin{array}{l}\text { sangat } \\
\text { sesuai }\end{array}$ \\
\hline $\begin{array}{l}\text { Memenuhi } \\
\text { Kebutuhan }\end{array}$ & 106 & 3,42 & 137 & 4,42 & 77 & sesuai \\
\hline $\begin{array}{l}\text { Waktu } \\
\text { Distribusi }\end{array}$ & 129 & 4,16 & 136 & 4,39 & 95 & $\begin{array}{l}\text { sangat } \\
\text { sesuai }\end{array}$ \\
\hline Warna Beras & 95 & 3,06 & 138 & 4,45 & 69 & Sesuai \\
\hline $\begin{array}{l}\text { Aroma } \\
\text { Beras }\end{array}$ & 98 & 3,16 & 133 & 4,29 & 74 & Sesuai \\
\hline $\begin{array}{l}\text { Kebersihan } \\
\text { Beras }\end{array}$ & 56 & 1,81 & 140 & 4,52 & 40 & $\begin{array}{c}\text { kurang } \\
\text { sesuai }\end{array}$ \\
\hline $\begin{array}{l}\text { Kondisi } \\
\text { Telur }\end{array}$ & 108 & 3,48 & 126 & 4,06 & 86 & $\begin{array}{l}\text { sangat } \\
\text { sesuai }\end{array}$ \\
\hline $\begin{array}{l}\text { Sesuai } \\
\text { Harga }\end{array}$ & 119 & 3,84 & 135 & 4,35 & 88 & $\begin{array}{l}\text { sangat } \\
\text { sesuai }\end{array}$ \\
\hline $\begin{array}{l}\text { Adanya } \\
\text { Pendataan } \\
\end{array}$ & 116 & 3,74 & 133 & 4,29 & 87 & $\begin{array}{l}\text { sangat } \\
\text { sesuai }\end{array}$ \\
\hline Jumlah & & 34,55 & & 43,45 & & \\
\hline Rata-rata & & 3,45 & & 4,34 & & \\
\hline
\end{tabular}

Keterangan:

$\mathrm{BKi}=$ Bobot kinerja

$\mathrm{BK}=$ Bobot kepentingan

$\mathrm{TKi}=$ Tingkat kesesuaian

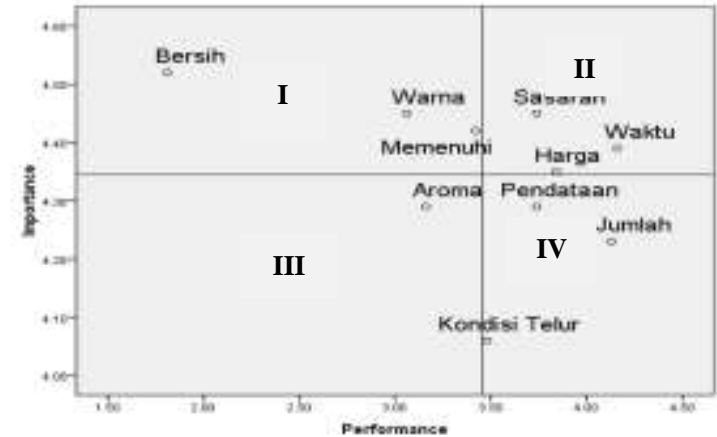

Gambar 2. Diagram kartesius IPA program BPNT

\section{Kuadran II (Pertahankan Prestasi)}

Kuadran II menunjukkan atribut-atribut yang dianggap penting oleh penerima manfaat dan telah berhasil melaksanakannya. Atribut-atribut yang masuk dalam kuadran II adalah atribut sasaran penerima, waktu pendistribusian dan sesuai harga.

\section{Kuadran III (Prioritas Rendah)}

Kuadran III menunjukkan bahwa atribut-atribut yang dianggap kurang penting. Atribut-atribut yang masuk dalam kuadran III adalah atribut aroma beras sebagai bagian dari atribut tepat mutu.

\section{Kuadran IV (Berlebihan)}

Kuadran IV menunjukkan bahwa atribut-atribut yang dinilai kurang penting, akan tetapi pelaksanaanya berlebihan. Atribut-atribut yang masuk dalam kudaran IV adalah atribut sesuai jumlah, kondisi telur dan adanya pendataan administrasi.

\section{KESIMPULAN}

Sistem distribusi dari program bantuan Rastra dan BPNT masuk dalam kategori distribusi semi langsung. Dari hasil efisiensi distribusi pada program Rastra sebesar 0,06 dan pada program BPNT sebesar 0,04 yang berarti bahwa pendistribusian kedua program bantuan pemerintah ini dinyatakan efisien. Nilai dengan menggunakan metode CSI diketahui bahwa program Rastra berada pada kriteria cukup tepat yaitu sebesar 54,36 persen, sedangkan pada program BPNT berada pada kriteria tepat yaitu sebesar 68,94 persen, hasil perhitungan tingkat kesesuaian antara kinerja dan harapan dengan metode IPA pada program Rastra atribut kurang sesuai (38 persen) adalah aribut tepat jumlah, sedangkan program BPNT atribut kurang sesuai (40 persen) adalah atribut kebersihan beras. 


\section{DAFTAR PUSTAKA}

Downey WD dan Erickson SP. 1992. Manajemen Agribisnis. Diterjemahkan oleh R. Ganda. S. dan A. Sirait. Erlangga. Jakarta.

Ekafitri W, Hasyim AI, dan Soelaiman A. 2014. Analisis efektifitas dan efisiensi distribusi beras miskin pada sentra penduduk miskin di Provinsi Lampung. Jurnal Ilmu Ilmu Agribisnis, 2(1):16-23. http://jurnal.fp.unila.ac.id/index.php/JIA/articl e/view/556. [2 Maret 2019].

Ghozali, I. 2002. Analisis Multivariate dengan Program SPSS. Badan Penerbit Universitas Diponegoro. Semarang.

Junaidi MS, Setiawan MS, dan Prastiwi WD. 2017. Komparasi kepuasan penerima bantuan pangan non tunai dan penerima rastra di Kecamatan Cakung, Jakarta Timur. Jurnal Ilmiah Econosains, 15(2):273-288. https://www.researchgate.net/publication/3224 42607_KOMPARASI_KEPUASAN_PENERI MA_KARTU_BANTUAN_PANGAN_NON_ TUNAI_DAN_PENERIMA_RASTRA_DI_K ECAMATAN_CAKUNG_JAKARTA_TIMU R. [4 Maret 2019].

Nugroho, I. dan Dahuri R. 2004. Pembangunan Wilayah : Perspektif Ekonomi, Sosial dan Lingkungan. LP3ES. Jakarta.

Septian MD, Bahri TS dan Makmur T. 2013. Analisis efektifitas dan efisiensi distribusi beras miskin (raskin) di Kecamatan Trienggadeng Kabupaten Pidie Jaya. Jurnal
Agrisep, 14(1):70-79. http://jurnal.unsyiah.ac.id/agrisep/article/view 1910. [2 Maret 2019].

Silalahi A, Salmiah, dan Roem HM. 2014. Evaluasi efektivitas dan efisiensi distribusi raskin berbasis sikap rumah tangga sasaran penerima manfaat (RTS-PM) (Studi Kasus: Desa Hamparan Perak Kecamatan Hamparan Perak Kabupaten Deli Serdang). Journal of Agriculture and Agribusiness Socioeconomics. 3(6):1-15. https://jurnal.usu.ac.id/index.php/ ceress/article/view/8213. [4 Maret 2019].

Sufren dan Natanel. 2013. Mahir Menggunakan SPSS Secara Otodidak. PT Elex Media Komputindo. Jakarta.

Sugiyono. 2007. Statistika Untuk Penelitian. Alfabeta. Cetakan Kesebelas. Bandung.

Supranto, J. 2006. Pengukuran Tingkat Kepuasan Pelanggan untuk Menaikkan Pangsa Pasar. PT Rineka Cipta. Jakarta.

Swastha, B. 2002. Manajemen Pemasaran. Edisi Kedua. Cetakan Kedelapan. Penerbit Liberty. Jakarta.

Thamrin M, Novita D, dan Tanjung DA. 2017. Analisis tingkat kesejahteraan dan tingkat kepuasan rumah tangga sasaran penerima manfaat program raskin. Jurnal Ilmu Pertanian, 20(3):230-238. https://media.neliti.com/media/publications/51 026-ID-efektivitas-pelaksanaan-raskin.pdf. [6 Maret 2019]. 